\title{
Equivalence in Translation Theories: A Critical Evaluation
}

\author{
Despoina Panou \\ Department of Education, University of Leicester, UK
}

\begin{abstract}
The concept of equivalence can be said to hold a central position in translation studies. Nevertheless, it has been a rather controversial one, causing many heated debates among translators as to its nature, definition and applicability. The aim of the present paper is to provide a critical evaluation of the most influential equivalence theories that have been proposed by scholars in the field, such as Vinay and Darbelnet (1958), Jakobson (1959), Nida and Taber (1969), Catford (1965), House (1997), Koller (1979), Newmark (1981), Baker (1992), and finally, Pym (2010). These theories are presented so as to provide a better understanding of how the concept evolved. It is concluded that the usefulness or not of the concept of equivalence to the translation process varies according to the stance of the translators concerned on what they regard are the virtues of equivalence itself.
\end{abstract}

Index Terms - equivalence, translation theories, source-language, target-language

\section{INTRODUCTION}

The process of translation has existed for millennia, thus facilitating both linguistic and cultural transfer. As a discipline, however, it began to develop in the second half of the twentieth century under the name "translation studies" which was proposed by the scholar James Holmes (1972). This term was widely accepted because it envisaged translation as a broad discipline shifting emphasis to neglected areas of translation such as interpreting and translator training. Perhaps, the biggest contribution of James Holmes (1988) lies in his attempt to draw the map of the 'territory' of translation studies. On closer inspection of the map, translation studies can be divided into two main areas; that is, pure and applied. There is a dual objective of pure translation studies; firstly, to provide a description of the various translation phenomena as these occur; and, secondly, to develop general principles through which these phenomena can be adequately explained. The former objective falls under the rubric of descriptive translation studies (DTS) and the latter under the rubric of translation theory, both being subsections of pure translation studies.

Furthermore, descriptive translation studies focus on three areas of research, namely, product-oriented DTS (textcentered studies which aim at investigating existing translations), process-oriented DTS (studies which are primarily interested in the mental processes that occur in translation) and function-oriented DTS (studies which seek to describe the function of translations in the target sociocultural situation). The results of DTS research can then be applied to translation theory to develop either a general translation theory or partial translation theories restricted according to medium (human vs. machine translation), area (specific linguistic or cultural groups), rank (focusing on specific linguistic levels, such as that of the word or the sentence), text-type (dealing with specific genres, for instance literary vs. business translation), time (dealing with particular periods of time) and problem (dealing with a specific translation problem, such as metaphor translation).

The 'applied' subdivision of Holmes' map has a more practical orientation and is mainly concerned with translation training (referring to teaching methods, testing techniques and curriculum planning), translation aids (referring to IT applications, dictionaries, translation software, on-line databases and the use of the internet), translation policy (drawing on the role of both translators and translations in society, as well as on the place and role of translating in society) and translation criticism (mainly addressing issues of revision and evaluation of translations).

It is worth mentioning that theoretical, descriptive and applied areas of translation studies influence one another and are dialectical in nature. This view is in direct opposition to Toury's thesis that translator training and criticism do not have a central position in translation studies but are viewed as 'extensions' of the discipline. In particular, Toury (1995) holds that the poles of theoretical and descriptive translation studies on the one hand, and what he names the 'Applied Extensions', on the other, have a unidirectional relationship.

Although Holmes' map has been criticised (Pym, 1998; Vandepitte, 2008), it could be argued that Holmes' divisions offer a flexible separation of the various areas of translation studies, thus indicating the great potential of the discipline. His simple, scientifically-framed and hierarchically-arranged categories not only identify but also interrelate the multiplicity of things that can be done in translation studies. But although, historically, this could be viewed as a legitimate point of departure, it should be mentioned that what translation studies represent simply cannot be depicted in this one map, since the discipline continues to evolve dynamically, thus revealing ever more of its interdisciplinary character as time goes on. Despite of its versatility, the concept of equivalence has always been an intriguing issue in the discipline of translation studies as will be subsequently discussed. 


\section{THE CONCEPT OF EQUivalENCE}

The concept of equivalence has been of particular concern to translation scholars since it has been inextricably linked with both definitional and practical aspects of translating. Becoming an essential feature of translation theories in the 1960s and 1970s, equivalence was meant to indicate that source text (henceforth ST) and target text (henceforth TT) share some kind of 'sameness'. The question was as to the kind and degree of sameness which gave birth to different kinds of equivalence. In what follows, an attempt will be made to critically analyze the equivalence paradigm as was conceptualized by the following scholars in the field, namely, Vinay and Darbelnet (1958), Jakobson (1959), Nida and Taber (1969), Catford (1965), House (1997), Koller (1979), Newmark (1981), Baker (1992), and finally, Pym (2010).

\section{A Critical Evaluation of the Concept of Equivalence}

\section{A. Vinay and Darbelnet}

Jean-Paul Vinay and Jean Darbelnet produced their Stylistique Comparée du Françaiset de l' Anglais (1958) which is a comparative stylistic analysis of the different translation strategies and procedures used in French and English. In its English version, first published in 1995, they distinguish between direct and oblique translation, the former referring to literal translation and the latter to free translation (p. 84). Moreover, they propose seven procedures, the first three covered by direct translation and the remaining four by oblique translation. These procedures are: borrowing, calque, literal translation, transposition, modulation, equivalence and adaptation. In particular, it is argued that equivalence is viewed as a procedure in which the same situation is replicated as in the original but different wording is used (Vinay and Darbelnet, 1995, p. 32). Through this procedure, it is claimed that the stylistic impact of the source-language (henceforth SL) text can be maintained in the target-language (henceforth TL) text. Hence, when dealing with proverbs, idioms and clichés, equivalence for them is sought at the level of sense and not image. For example, the idiom comme un chien dans un jeu de quilles meaning literally like a dog in a set of skittles could be translated like a bull in a china shop (cited in Munday, 2001, p. 58).

Furthermore, Vinay and Darbelnet (1995) consider as a necessary and sufficient condition for equivalent expressions between language pairs to be acceptable to be listed in a bilingual dictionary "as full equivalents" (p. 255). Nevertheless, they realized the utopia of such a statement by admitting that glossaries and collections of idiomatic expressions are non-exhaustive (p. 256). In other words, the rendering of an equivalent of an expression in the SL text in a dictionary or glossary does not suffice or guarantee a successful translation since the context surrounding the term in question plays an equally important role in determining the translation strategy employed. They conclude by stating that the situation is what determines the need for creating equivalences. So translators are encouraged to firstly look in the situation of the ST in order to come up with a solution (p. 255).

\section{B. Jakobson}

The structuralist Roman Jakobson (1959) maintains that there are three kinds of translation, that is, intralingual (rewording or paraphrasing within one language), interlingual (rewording or paraphrasing between two languages), and intersemiotic (rewording or paraphrasing between sign systems). It is interlingual translation that has been the focus of translation studies.

More specifically, when addressing the thorny problem of equivalence in meaning between words in different languages, he immediately stresses the fact that there can be no full equivalence between two words (Jakobson, 1959/2000, p. 114). He cites the example of cheese in English by saying that it is not identical to the Russian syr-the concept of cottage cheese not being included in the latter. Jakobson does not propose that translation is impossible but rather pinpoints the differences in the structure and terminology of languages.

On closer inspection of the aforementioned views on equivalence, one may claim that there are some similarities between Vinay and Darbelnet's theory of translation and Jakobson's. Adopting a linguistic approach, they both argue that translation is possible despite cultural or grammatical differences between SL and TL. They both recognize the fact that the role of the translator should not be neglected and acknowledge some limitations of the linguistic approach, thus allowing the translator to also rely on other procedures that will ensure a more effective and comprehensive rendering of the ST message in the target text.

\section{Nida and Taber}

The contribution of Eugene Nida in the field of translation studies cannot be overstressed, with his two famous books in the 1960s: Toward a Science of Translating (1964) and the co-authored The Theory and Practice of Translation (Nida and Taber, 1969), attempting to give a more "scientific" sense to translation. Borrowing theoretical concepts from semantics and pragmatics, and being influenced by Chomsky's generative-transformational grammar (1965), Nida adopts a more systematic approach to exploring the field of translation studies.

With regard to equivalence, Nida maintains that there are two basic types of equivalence: (1) formal equivalence and (2) dynamic equivalence. In particular, Nida argues that in formal equivalence the TT resembles very much the ST in both form and content whereas in dynamic equivalence an effort is made to convey the ST message in the TT as naturally as possible. It could be argued that Nida is in favour of dynamic equivalence since he considers it to be a more 
effective translation procedure. This comes as no surprise given the fact that Nida was, at the time at which he proffered his views about equivalence, translating the Bible, and hence trying to produce the same impact on various different audiences he was simultaneously addressing. Nida's preference is more clearly stated in Nida and Taber's edition (1969) since it is argued that dynamic equivalence in translation goes beyond correct communication of information (p. 25).

As Munday (2001) points out, Nida is credited for introducing a receptor-based direction to the task of translating (p. 42). Nevertheless, Nida's theory has been severely criticized for several reasons. In more detail, Lefevere (1993, p. 7) holds that equivalence is still focused on the word-level whereas Broeck (1978) wonders how it is possible to measure the equivalent effect since no text can have the same effect or elicit the same response in two different cultures in different periods of time (p. 40). Perhaps, the fiercest critic of Nida's work is Edwin Gentzler, who dedicates a whole chapter to the 'science' of translation in his Contemporary Translation Theories (2001), using quotation marks around the word science perhaps in order to indicate his own sceptical views on the scientific virtue of translation methods. Gentzler overtly criticizes Nida for using the concept of dynamic equivalence in order to proselytize readers, regardless of their culture, to endorse the ideas of Protestant Christianity.

Despite these criticisms, it could be concluded that Nida moved a long way forward from the position of his predecessors because he was able to produce a systematic and analytical procedure for translators working with all kinds of texts and, more importantly, brought into the translation game, the readers; that is, the receptors, as well as their cultural expectations.

\section{Catford}

Catford's main contribution in the field of translation studies lies in the introduction of his idea of types and shifts of translation. Shifts refer to the changes that take place during the translation process. More specifically, Catford describes very broad types of translation according to three criteria. Firstly, full translation is contrasted with partial translation which differs according to the extent of translation. Secondly, total translation differs from restricted translation according to the levels of language involved in translation, and, thirdly, Catford distinguishes between rank-bound translation and unbounded translation, depending on the grammatical or phonological rank at which equivalence is established.

Since the interest of this paper lies in equivalence, I will be mainly concerned with the third type of translation, and I will provide an analysis of the notion of shifts. With regard to translation shifts, Catford (1965) defines them as departures from formal correspondence when translating from the SL to the TL (p. 73). Moreover, he maintains that there are two main types of translation shifts, that is, level shifts (where an SL item at one linguistic level, for example grammar, has a TL equivalent at a different level, for instance lexis) and category shifts, which are divided into (a) structure-shifts involving change in grammatical structure, (b) unit-shifts involving changes in rank, (c) class-shifts involving changes in class, and (d) intra-system shifts which occur internally when source and target language systems share the same constitution but a non-corresponding term in the TL is selected when translating (p. 80).

Catford was severely criticized for holding a largely linguistic theory of translation. Snell-Hornby (1988) puts forward the claim that linguistics should not be considered as the only discipline which enables translation to take place, but that cultural, situational and historical factors should also be taken into consideration (p. 19-20). Moreover, she goes on to claim that Catford's definition of textual equivalence is "circular", his reliance on bilingual informants "hopelessly inadequate" and his example sentences "isolated and even absurdly simplistic" (cited in Leonardi, 2007, p. 87). However, Malmkjaer (2005) insightfully observes that one should bear in mind that when Catford (1965) defines translation as the replacement of SL textual material by TL equivalent textual material (p. 20) he does not mean equivalent in meaning (cited in Malmkjaer, 2005, p. 24).

\section{E. House}

Adopting pragmatic theories of language use, House (1997) has come up with a translation model in which the basic requirement for equivalence of ST and TT is that original and translation should match one another in function. This function should be achieved by employing equivalent pragmatic means. The translation is only, therefore, considered to be adequate in quality if it matches the 'textual' profile and function of the original.

In more detail, carrying out contrastive German-English discourse analyses, House has distinguished between two basic types of translation, namely, overt translation and covert translation. As the term itself denotes, an overt translation points to a TT that consists of elements that 'betray' that it is a translation. On the other hand, a covert translation is a TT that has the same function with the ST since the translator has made every possible effort to alleviate cultural differences. In conclusion, it could be argued that House's theory seems more flexible than Catford's since it incorporates the pragmatic aspect of translation by using authentic examples.

\section{F. Koller}

One of the most prominent German scholars working in the field of translation studies is Werner Koller. Koller's (1979) Einführung in die Übersetzungswissenschaft (Introduction into the Science of Translation) is a detailed examination of the concept of equivalence and its linked term correspondence. In particular, correspondence involves the comparison of two language systems where differences and similarities are described contrastively, whereas equivalence deals with equivalent items in specific ST-TT pairs and contexts. 
In an effort to answer the question of what is equivalent to what, Koller (1979) distinguishes five different types of equivalence: (a) denotative equivalence involving the extralinguistic content of a text, (b) connotative equivalence relating to lexical choices, (c) text-normative equivalence relating to text-types, (d) pragmatic equivalence involving the receiver of the text or message, and, finally, (e) formal equivalence relating to the form and aesthetics of the text (p. 186-191). Having identified different types of equivalence, Koller (1979) goes on to argue that a hierarchy of values can be preserved in translation only if the translator comes up with a hierarchy of equivalence requirements for the target text (p. 89). Although the hierarchical ordering of equivalences is open to debate, Koller's contribution to the field of translation studies is acknowledged for bringing into translators' attention various types and ways in which the then fashionable desideratum of equivalence may be achieved.

\section{G. Newmark}

This paper would have been incomplete without reference to Peter Newmark, one of the founders of the Institute of Linguists and a fervent advocate for the professionalization of translators. Newmark's Approaches to Translation (1981) and A Textbook of Translation (1988) do not aim to promote any monolithic translation theory but rather attempt to describe a basis for dealing with problems encountered during the translation process. More specifically, Newmark replaces Nida's terms of formal and dynamic equivalence with semantic and communicative translation respectively. The major difference between the two types of translation proposed by Newmark is that semantic translation focuses on meaning whereas communicative translation concentrates on effect. In other words, semantic translation looks back at the ST and tries to retain its characteristics as much as possible. Its nature is more complex, detailed and there is also a tendency to over-translate. On the other hand, communicative translation looks towards the needs of the addressees, thus trying to satisfy them as much as possible. In this respect, communicative translation tends to under-translate; to be smoother, more direct and easier to read. Hence, in semantic translation a great emphasis is placed on the author of the original text whereas communicative translation is meant to serve a larger readership. It should be pointed out that during the translation process, communicative translation need not be employed exclusively over semantic or vice versa. It may well be the case in a literary text that a particular sentence requires communicative translation whereas another sentence from the same text may require a semantic one. Hence, the two methods of translation may be used in parallel, with varying focuses where each is employed.

Moreover, Newmark (1981) strongly believes that literal translation is the best approach in both semantic and communicative translation (p. 39). However, he is careful to note that when there is a conflict between the two forms of translation, then communicative translation should be favoured in order to avoid producing an abnormal, odd-sounding or semantically inaccurate result. In order to illustrate his point, he uses the example of the common sign bissiger Hund and chien méchant, which should be translated communicatively as beware the dog! instead of semantically as dog that bites! and bad dog! so that the message is communicated effectively (p. 39).

Although Newmark has been criticized for his prescriptivism (Munday, 2000, p. 46), the wealth of practical examples in his books constitutes a good advisory guide for both trainees and established translators.

\section{H. Baker}

Mona Baker in her influential book In Other Words (1992) addresses the vexing issue of equivalence by adopting a more neutral approach when she argues that equivalence is a relative notion because it is influenced by a variety of linguistic and cultural factors (p. 6). In particular, the chapters of her book are structured around different kinds of equivalence, that is, at the level of word, phrase, grammar, text and pragmatics. Hence, terms such as grammatical, textual and pragmatic equivalence come up. In more detail, a distinction is made between word-level and above-worldlevel equivalence. Adopting a bottom-up approach, Baker acknowledges the importance of individual words during the translation process, since the translator looks firstly at the words as single units in order to find their equivalent in the TL. Baker goes on to provide a definition of the term word referring to its complex nature since a single word can sometimes be assigned different meanings in different languages. Consequently, parameters such as number, gender and tense should be taken into consideration when translating a word (p. 11-12).

Grammatical equivalence refers to the diversity of grammatical categories across languages and the difficulty of finding an equivalent term in the TT due to the variety of grammatical rules across languages. In fact, she stresses that differences in grammatical structures may significantly change the way the information or message is carried across. As a consequence, the translator may be forced to add or delete information in the TT because of the lack of specific grammatical categories. Some of the major categories that often pose problems for translators are number, voice, person, gender, tense and aspect.

On the other hand, textual equivalence refers to equivalence that may be achieved between a ST and TT in terms of cohesion and information. Baker argues that the feature of texture is of immense importance for the translators since it facilitates their comprehension and analysis of the ST and helps them to produce a cohesive and coherent text in the TL. The translators' decision to maintain (or not) the cohesive ties as well as the coherence of the SL text mainly rests on three main factors; the target audience, the purpose of the translation and the text type.

Lastly, pragmatic equivalence deals mainly with implicature. Drawing from Grice (1975), Baker argues that the term implicature is used to refer to what is implied and not to literal meaning. In other words, the focus of interest is not on what is explicitly said but what is intended or implied in a given context. The role of the translator is to work out the 
meaning of implicatures if these exist in the ST and transfer them to the extent that this is possible. The primary aim of the translator should be to recreate the intended message of the SL in such a way so that it becomes accessible and comprehensible to the target audience.

Baker's contribution to the field of translation studies is widely acknowledged on account of her providing a systematic approach to training translators through the elaboration of specific strategies that can be used to deal with the numerous translation problems translators encounter daily. Hence, by addressing both theoretical and practical issues in translation, this book forms a sound basis for translators.

\section{Pym}

Lastly, Pym (2010) makes his own contribution to the concept of equivalence by pointing out that there is no such thing as perfect equivalence between languages and it is always assumed equivalence (p. 37). In particular, for Pym (2010) equivalence is a relation of "equal value" between an ST segment and a TT segment and can be established on any linguistic level from form to function (p. 7). He goes on to distinguish between natural and directional equivalence. Natural equivalence exists between languages prior to the act of translating, and, secondly, it is not affected by directionality (p. 7). On the other hand, theories of directional equivalence give the translator the freedom to choose between several translation strategies which are not dictated by the ST. Although there are usually many ways of translating, the strategies for directional equivalence are reduced into two opposing poles; one adhering to SL norms and the other to TL norms. Perhaps, the most important assumption of directional equivalence is that it involves some kind of assymetry since when translating one way and creating an equivalent does not imply the creation of the same equivalent when translating another way (p. 26).

\section{CONCLUSION}

In conclusion, it could be argued that many translation theories are based on two opposing ways of translating. For example, Nida distinguishes between formal and dynamic equivalence, Newmark between semantic and communicative translation, Catford between formal correspondence and textual equivalence, House between overt and covert translation and Pym between natural and directional equivalence. These bipolar views of equivalence soon faded away and more attractive translation paradigms came to the forefront. Contrary to linguistic-oriented approaches to translation which assume that the source text occupies a supreme position and that it is considered to be of crucial importance in determining not only the translation process but also the extent to which it has been successful, target-oriented approaches view the source text as the point of departure for the translation process and mostly focus on the cultural, historical, and socio-political factors surrounding translation, thus looking at it as a culture-bound phenomenon. Despite of its shortcomings, it should be stressed that equivalence is still one of the pivotal definitory axes of translation since it functions as a reminder of the central problems a translator encounters during the translation process.

\section{REFERENCES}

[1] Baker, M. (1992). In Other Words. A Coursebook on Translation. London: Routledge.

[2] Broeck, R. van den. (1978). The concept of equivalence in translation theory. Some critical reflections. In Holmes, J.S., Lambert, J. and Broeck, R. van den (eds.) Literature and Translation. Leuven: Academic, 29-47.

[3] Catford, J.C. (1965). A Linguistic Theory of Translation. London: Oxford University Press.

[4] Chomsky, N. (1965). Aspects of the Theory of Syntax. Cambridge, MA: MIT Press.

[5] Gentzler, E. (2001). Contemporary Translation Theories. Clevedon: Multilingual Matters.

[6] Holmes, J.S. (1972). The Name and Nature of Translation Studies. Unpublished manuscript. Amsterdam: Translation Studies Section, Department of General Studies.

[7] Holmes, J.S. (1988/2000). The name and nature of translation studies. In Venuti, L. (ed) (2000), The Translation Studies Reader. London and New York: Routledge, 172-185.

[8] House, J. (1997). Translation Quality Assessment: A Model Revisited. Tübingen: Narr.

[9] Jakobson, R. (1959/2000). On linguistics aspects of translation. In Venuti, L. (ed.) (2000), The Translation Studies Reader. London and New York: Routledge, 113-118.

[10] Grice, H.P. (1975). Logic and conversation. In Cole, P. and Morgan, J. (eds.) Syntax and Semantics 3: Pragmatics. New York: Academic Press, 41-58.

[11] Koller, W. (1979). Einführung in die Übersetzungswissenschaft. Heidelberg: Quelle and Meyer.

[12] Lefevere, A. (1993). Translating Literature: Practice and Theory in a Comparative Literature Context. New York: The Modern Language Association of America.

[13] Leonardi, V. (2007). Gender and Ideology in Translation. Do Women and Men Translate Differently? Bern and Oxford: Peter Lang.

[14] Malmkjaer, K. (2005). Linguistics and the Language of Translation. Edinburgh: Edinburgh University Press.

[15] Munday, J. (2000). Introducing Translation Studies. London and New York: Routledge.

[16] Newmark, P. (1981). Approaches to Translation. Oxford and New York: Pergamon Press.

[17] Newmark, P. (1988). A Textbook of Translation. New York: Prentice Hall.

[18] Nida, E. (1964). Towards a Science of Translating. Leiden: E.J. Brill.

[19] Nida, E. (1969). Science of translation. Language 45, 483-498.

[20] Nida, E. and Taber, C.R. (1969). The Theory and Practice of Translation. Leiden: E.J. Brill. 
[21] Pym, A. (1998). Method in Translation History. Manchester: St Jerome.

[22] Pym, A. (2010). Exploring Translation Theories. London and New York: Routledge.

[23] Snell-Hornby, M. (1988). Translation Studies: An Integrated Approach. Amsterdam and Philadelphia: John Benjamins.

[24] Toury, G. (1995). Descriptive Translation Studies and Beyond. Amsterdam and Philadelphia: John Benjamins.

[25] Vandepitte, S. (2008). Remapping Translation Studies: towards a translation studies ontology. Meta 53(3), 569-588.

[26] Vinay, J.P. and Darbelnet, J. (1958). Stylistique Comparée du Francais et de l' Anglais: Méthode de Traduction. Paris: Didier. (Transl. and ed. by Sager, J.C. and Hamel, M.J. (1995) as Comparative Stylistics of French and English: A Methodology for Translation. Amsterdam and Philadephia: John Benjamins.)

Despoina Panou is a Ph.D. student at the University of Lecester. She has a B.A. in English Language and Literature (with distinction) and an M.A. in Translation-Translatology (with distinction) from the University of Athens. She also has an M.A. in Linguistics-TESOL (with merit) from the University of Surrey. Her research interests are foreign language teaching, translation, and the use of figurative/idiomatic language in business discourse. 